\title{
Optimization of electrochemical synthesis conditions for dense and doped ceria thin films
}

\author{
Kai Kamada ${ }^{\mathrm{a}, \mathrm{b},{ }^{*}}$, Naoya Enomoto ${ }^{\mathrm{b}}$, Junichi Hojo ${ }^{\mathrm{b}}$ \\ ${ }^{a}$ Department of Materials Science and Engineering, Faculty of Engineering, Nagasaki \\ University, 1-14 Bunkyo-machi, Nagasaki 852-8521, Japan \\ b Department of Applied Chemistry, Faculty of Engineering, Kyushu University, 744 \\ Motooka, Nishi-ku, Fukuoka 819-0395, Japan
}

*Corresponding author: kkamada@nagasaki-u.ac.jp

\begin{abstract}
In the present study, the appropriate electrolysis conditions were determined for attaining doped ceria thin films with a high density and adhesion in an aqueous solution containing of $\mathrm{Ce}^{3+}$ and $\mathrm{Sm}^{3+}$ ions. Based on a comparison of the anodic and cathodic polarizations, while the former only induced the deposition of $\mathrm{Ce}^{3+}$, the latter accomplished the simultaneous deposition of $\mathrm{Ce}$ and $\mathrm{Sm}$ species. Under an applied cathodic bias below the hydrogen evolution potential, the $\mathrm{Ce}^{3+}$ and $\mathrm{Sm}^{3+}$ were reacted with $\mathrm{OH}^{-}$ions generated by the reduction of water molecules, and then were deposited on the electrode as a hydroxide. The hydroxide was subsequently oxidized and dehydrated to form the ceria-based thin layer. The morphologies of the as-deposited films were significantly altered on the basis of the applied potential. Moreover, the addition of acetic acid to the electrolysis bath caused the production of a transparent, dense, and adherent film. The XRD pattern and Raman spectrum of the thin film revealed that the film was crystallized as the fluorite structure without any heat treatment, and $\mathrm{Sm}^{3+}$ is substituted at the $\mathrm{Ce}^{4+}$ site. Moreover, the Sm content in the film could be easily controlled by the metal concentration in the solution.
\end{abstract}

Keywords: soft solution processing; doped ceria; electrochemical coating; thin film; anti-corrosion 


\section{Introduction}

Thin films of pure ceria $\left(\mathrm{CeO}_{2}\right)$ and its solid solutions have many important characteristics, such as ion conducting [1], electrochromic [2], and UV light shielding $[3,4]$ properties. Recently, $\mathrm{CeO}_{2}$ films have attracted attention as anti-corrosion dopant [5] or as conversion layer [6,7]. The dense ceria films with a strong adhesion to a substrate and without structural defects (pinholes and/or cracks) are suitable for the applications mentioned above. Numerous fabrication methods including sol-gel, sputtering, chemical solution techniques, etc., have been reported to prepare ceria based thin films. Among them, the electrochemical formation of ceria thin films is expected to become more important in the future because it is a low energy solution process carried out under environmentally friendly conditions. Moreover, the characteristic states of the films can be easily controlled by varying the preparation conditions, such as potential, current density, temperature, and $\mathrm{pH}$ used during the electrolysis. Until now, high-precision oxide films, such as epitaxial [8,9], superlattice [10], quantum dot $[11,12]$ and noble metal doped films [13] have been prepared by the electrochemical method.

In the past decades, a number of reports have dealt with the electrochemical preparation of ceria thin films. Conventional electrolysis was performed in aqueous solutions of $\mathrm{Ce}^{3+}$ salts, and $\mathrm{CeO}_{2}$ films were deposited via electrochemical reactions on conductive substrates. It has been demonstrated that $\mathrm{CeO}_{2}$ films can be electrodeposited by either cathodic or anodic processes [14-19]. In the former case, applying a more negative bias than the hydrogen evolution potential of $\mathrm{H}_{2} \mathrm{O}$ raises the $\mathrm{pH}$ near the electrode surface, and then $\mathrm{Ce}^{3+}$ is precipitated as a hydroxide on the electrode surface. Finally, $\mathrm{Ce}(\mathrm{OH})_{3}$ is transformed into $\mathrm{CeO}_{2}$ by oxidation and dehydration. Naturally, the cathodic method is applicable to not only $\mathrm{Ce}^{3+}$, but also other metal ions taking part in the precipitation at high $\mathrm{pH}$. On the other hand, anodic polarization allows the direct electrochemical oxidation of $\mathrm{Ce}^{3+}$ to insoluble $\mathrm{Ce}(\mathrm{OH})_{4}\left(\mathrm{CeO}_{2} \cdot \mathrm{nH}_{2} \mathrm{O}\right)$, and is useful for other limited metal ions which are oxidized to insoluble higher valence states [20-23].

Even though the electrochemical processing of pure ceria thin films has been energetically studied [24-27], there are few reports on the thin films of ceria-based solid solution, i.e., doped ceria, within our knowledge [28,29]. Since the ion conduction and electrochromism of ceria appear only after the incorporation of other metal ions, the metal ion doping into ceria is useful to increase the availability of ceria. It is pointed out that the electrochemically prepared ceria thin films have some disadvantages based on the processing in aqueous solution, i.e., (1) development of structural defects due to gas 
evolution from the electrode surface as a side reaction, and (2) weak adherence to the substrate $[18,24]$. Therefore, in this study, the electrochemical conditions for synthesis of doped ceria thin films ( $\mathrm{Sm}$-doped $\mathrm{CeO}_{2}$ ) showing dense and adherent characteristics have been optimized by controlling the bath composition and electrochemical parameters. As a result, we demonstrated that the cathodic polarization in a $\mathrm{Ce}^{3+}$ solution containing acetate ions simultaneously produces dopant incorporation and densification of the ceria thin films.

\section{Experimental}

The electrochemical preparation of Sm-doped $\mathrm{CeO}_{2}$ thin films was carried out in a single-compartment glass cell, in which Sm doping is known to enhance the oxide ion conductivity of $\mathrm{CeO}_{2}$. A Pt foil was used as the working electrode (apparent electrode area: $\left.1 \mathrm{~cm}^{2}\right)$. A Pt plate $\left(6 \mathrm{~cm}^{2}\right)$ and saturated $\mathrm{Ag} / \mathrm{AgCl}$ were used as the counter and reference electrodes, respectively. In this paper, the working electrode potentials refer to the reference electrode. The water used in all the processes was doubly deionized water. The electrolyte solution was prepared by mixing identical volumes of a $0.1 \mathrm{M}$ $\left(\mathrm{Ce}\left(\mathrm{NO}_{3}\right)_{3}+\mathrm{Sm}\left(\mathrm{NO}_{3}\right)_{3}\right)$ with $0.1 \mathrm{M} \mathrm{CH}_{3} \mathrm{COOH}$, i.e., $\left[\mathrm{Ce}^{3+}+\mathrm{Sm}^{3+}\right]=0.05 \mathrm{M}$, where metal fraction of $\mathrm{Sm}^{3+}\left(f_{\mathrm{Sm}}=\mathrm{Sm} /(\mathrm{Ce}+\mathrm{Sm})\right)$ was adjusted in the range of $0 \sim 0.5$ in mol. The co-existence of acetate ions in the electrolyte solution allows the metal ions to be stabilized as a complex ion. In order to promote the dissociation of acetic acid and the formation of complex ions between acetate ion and $\mathrm{Ce}^{3+}$, the solution $\mathrm{pH}$ was adjusted to 5 by the addition of a minute amount of $3 \mathrm{M} \mathrm{NaOH}$. Before electrolysis, the electrolyte solution was naturally aerated. Electrolysis was performed by applying a constant potential to the working electrode at $323 \mathrm{~K}$ for $1 \mathrm{~h}$. The obtained films were washed with water and dried under ambient conditions. The morphology and composition of the films was observed and analyzed by FE-SEM-EDS (Hitachi S-5200) with acceleration voltage of $5 \mathrm{kV}$. The X-ray diffraction (XRD) patterns for the samples were measured using a Rigaku RINT2200 with Ni-filtered $\mathrm{Cu}-\mathrm{K}_{\alpha}$ radiation operated at $40 \mathrm{kV}$ and $30 \mathrm{~mA}$. Laser Raman spectroscopy (JASCO NRS-2000, Ar laser, $\lambda=514.5$ $\mathrm{nm})$ was also employed for phase identification. The amount of $\mathrm{Ce}$ and $\mathrm{Sm}$ deposited was estimated by ICP-MS (Agilent 7500c) after dissolving a film in concentrated $\mathrm{HNO}_{3}$ solution.

\section{Results and Discussion}

\subsection{Electrochemical characterization}

To investigate the redox behaviors of $\mathrm{Ce}^{3+}$ and $\mathrm{Sm}^{3+}$ under an applied a potential, 
the anodic and cathodic polarization curves of the Pt working electrode from an open circuit potential (OCP: $+0.25 \mathrm{~V}$ ) were measured as shown in Fig. 1. Under anodic polarization, the broad peak centered at $+0.75 \mathrm{~V}$ was assigned to the oxidation of the $\mathrm{Pt}$ electrode, and oxygen gas evolution from the $\mathrm{H}_{2} \mathrm{O}$ molecules (OER) was confirmed above ca. $+1.0 \mathrm{~V}$. In the cathodic polarization curve, the small peaks due to the reduction of dissolved oxygen molecules and $\mathrm{NO}_{3}{ }^{-}$appeared, and hydrogen gas was generated below ca. $-0.5 \mathrm{~V}$ as a result of reduction of $\mathrm{H}_{2} \mathrm{O}$ and $\mathrm{H}^{+}$. On the basis of the comparison with the polarization curve for a metal-free solution, no electrochemical responses related to $\mathrm{Ce}^{3+}$ and $\mathrm{Sm}^{3+}$ were detected in Figure 1.

\subsection{Influence of cathodic potential on film formation}

The formation of thin films was confirmed at the constant applied potential above $+0.8 \mathrm{~V}$ (anodic) or below $-0.5 \mathrm{~V}$ (cathodic). Figure 2 shows the results of the EDS analysis of the thin films prepared under the anodic or cathodic polarization in the mixed solution of $f_{S m}=0.5$. The characteristic X-ray of Ce was only detected and no presence of $\mathrm{Sm}$ was confirmed in the anodically deposited thin films. While the electrochemical oxidation of $\mathrm{Ce}^{3+}$ to $\mathrm{Ce}(\mathrm{OH})_{4}$ proceeds under an anodic bias, $\mathrm{Sm}^{3+}$ is impossible to be oxidized to a higher valence similar to other rare earth metals except for $\mathrm{Pr}^{3+}$. Consequently, the thin film formed by the anodic polarization included only oxidized Ce species. In contrast, the cathodic polarization resulted in the co-deposition of both Ce and Sm as shown in Fig. 2 (b). In this case, applying a more negative bias than the hydrogen evolution potential raises the $\mathrm{pH}$ near the electrode surface because of the production of hydroxide ions [14]. It appears that, as a result, $\mathrm{Ce}^{3+}$ and $\mathrm{Sm}^{3+}$ are simultaneously accumulated as a solid hydroxide on the electrode surface, because these metals show a similar precipitation behavior [30]. To fabricate the Sm-doped ceria thin films, the following sections will focus on the cathodic polarization and optimize the electrolysis conditions for attaining dense and adherent films.

Regardless of the metal ratio in the bath, the morphologies of the as-deposited thin films were dramatically changed depending on the cathodic potential during the electrolysis. Applying a more positive potential than $-0.4 \mathrm{~V}$ did not cause any deposition, and the films grown below $-0.6 \mathrm{~V}$ were thick and opaque, and consisted of granular deposits weakly attached to the Pt substrate. On the contrary, the Pt substrate was uniformly coated with yellowish transparent thin films after the electrolysis at the intermediate potential of about $-0.5 \mathrm{~V}$. Figure 3 shows the chronoamperometry for a thin film growth at $-0.5 \mathrm{~V}$ on the Pt working electrode in the mixed solution $\left(f_{S m}=0.5\right)$. The current density abruptly decreased during the initial stage of the electrolysis, and 
reached a steady state around $-0.08 \mathrm{~mA} / \mathrm{cm}^{2}$ after $5 \mathrm{~min}$. This indicates that the cathodic reactions were retarded by the insulating layer that was initially produced on the entire electrode surface. Therefore, it was suggested that the optimum electrode potential is ca. $-0.5 \mathrm{~V}$ to induce the homogeneous deposition of the film in the present electrolysis bath.

\subsection{Morphology and adhesion of film}

Figure 4 shows SEM micrographs of the surface and cross section of the film grown at $-0.5 \mathrm{~V}$ in the $f_{S m}=0.5$ solution, in which the surface image of the film deposited in the bath excluding acetic acid is also displayed. As shown in Figs. 4(a) and (b), the films homogeneously formed at $-0.5 \mathrm{~V}$ were composed of densely packed fine particles (diameter $\sim 10^{1} \mathrm{~nm}$ ) and had no discernible structural defects (cracks, pinholes and peelings). The thickness was about $100 \mathrm{~nm}$ under the present condition. On the contrary, the absence of acetic acid in the bath caused the partial peeling of the deposits and the precipitation of larger platelet particles with cracks due to the hydrogen gas evolution (Fig. 4(d)). Such a morphology was quite similar to that of the films prepared at potentials more negative than $-0.6 \mathrm{~V}$ as stated above. Based on these facts, the addition of acetic acid to the electrolysis bath plays an important role in the densification of the as-deposited layer. According to the literatures [24-26], it is predicted that acetate ions behave as a complex agent for $\mathrm{Ce}^{3+}$ and $\mathrm{Sm}^{3+}$. Assuming the electrolysis bath containing only $\mathrm{Ce}^{3+}$ as the source of the film, the $\mathrm{Ce}^{3+}$ seems to be coordinated with up to four acetate ligands; $\mathrm{Ce}^{3+}, \mathrm{Ce}(\mathrm{OH})^{2+}, \mathrm{Ce}(\mathrm{Ac})^{2+}, \mathrm{Ce}(\mathrm{Ac})_{2}{ }^{+}, \mathrm{Ce}(\mathrm{Ac})_{3}, \mathrm{Ce}(\mathrm{Ac})_{4}{ }^{-}$, where $\mathrm{Ac}^{-}$is the acetate ion $\left(\mathrm{CH}_{3} \mathrm{COO}^{-}\right)$. As indicated by Switzer et al. [26], the predominant species in the electrolysis bath can be calculated using the ionization product of water, the dissociation constant for acetic acid, and the formation constants of the complex ions. As a result, the present solution $\left(0.05 \mathrm{M} \mathrm{Ce}^{3+}+0.05 \mathrm{M} \mathrm{Ac}^{-}, \mathrm{pH}=5\right)$ consists of $54.2 \%$ $\mathrm{Ce}^{3+}, 0.0 \% \mathrm{Ce}(\mathrm{OH})^{2+}, 39.4 \% \mathrm{Ce}(\mathrm{Ac})^{2+}, 6.1 \% \mathrm{Ce}(\mathrm{Ac})_{2}{ }^{2+}, 0.3 \% \mathrm{Ce}(\mathrm{Ac})_{3}$, and $0.0 \%$ $\mathrm{Ce}(\mathrm{Ac})_{4}{ }^{-}$. That is, over $40 \%$ of the Ce species is complexed with acetate ligands. Hence, the presence of the acetate complex would significantly affect the deposition mechanism. For instance, $\mathrm{Ce}(\mathrm{OH})_{3}$ will be produced from $\mathrm{Ce}(\mathrm{Ac})^{2+}$ on the Pt surface during the electrolysis by the following chemical reaction:

$\mathrm{Ce}(\mathrm{Ac})^{2+}+3 \mathrm{OH}^{-} \leftrightarrow \mathrm{Ce}(\mathrm{OH})_{3}+\mathrm{Ac}^{-}$(1)

$K=\left[\mathrm{Ce}(\mathrm{OH})_{3}\right]\left[\mathrm{Ac}^{-}\right] /\left\{\left[\mathrm{Ce}(\mathrm{Ac})^{2+}\right]\left[\mathrm{OH}^{-}\right]^{3}\right\}$

where $K$ is the equilibrium constant of eq. (1), and $K_{\mathrm{Ce}(\mathrm{OH}) 3}$ and $K_{\mathrm{CeAc}}$ are the formation constants of $\mathrm{Ce}(\mathrm{OH})_{3}$ and $\mathrm{Ce}(\mathrm{Ac})^{2+}$, respectively. As $K_{C e A c}$ typically exceeds unity (log $K_{C e A c}=1.68$ [24]), the relationship of $\mathrm{K}<<K_{\mathrm{Ce}(\mathrm{OH}) 3}$ is determined, indicating that the 
existence of complex ions, such as $\mathrm{Ce}(\mathrm{Ac})^{2+}$, retards precipitation of the hydroxide. Consequently, the gradual growth of the hydroxide layer would bring about the formation of a homogeneous film. The addition of acetic acid seems to be also effective for the stabilization of $\mathrm{Sm}^{3+}$. Furthermore, the buffer action of the free acetate ions may relax the $\mathrm{pH}$ gradient near the $\mathrm{Pt}$ surface, resulting in nucleation of the hydroxide at a location closer to the electrode surface. In summary, the preparation of dense layers containing both $\mathrm{Ce}$ and $\mathrm{Sm}$ was realized by cathodic polarization in the bath with acetate ions. While a similar coordination effect of carboxylate ions had already been demonstrated in the cases of the anodic polarization for $\mathrm{CeO}_{2}$ deposition, the present study has first confirmed that the acetate ions are useful for improving the density of the film prepared by the cathodic polarization which is completely different mechanism from the anodic oxidation.

Adhesion to a substrate as well as density is one of the significant factors for the practical applications of doped ceria thin films. The ultrasonic impaction method was employed to qualitatively estimate the adhesion force. The film-coated Pt substrate was ultrasonicated $(60 \mathrm{~W})$ for $10 \mathrm{~min}$ in pure water. The particles deposited in the bath without acetic acid (Fig. 4(d)) had completely peeled off from the Pt substrate during the ultrasonication. In contrast, over $80 \%$ of the dense film as shown in Fig. 4(a, b) remained. Also, the films could only be detached by chemical dissolution or abrasion. These results qualitatively indicate that they had a strong adhesion to the substrate.

\subsection{Effect of bath composition}

The amounts of $\mathrm{Ce}$ and $\mathrm{Sm}$ deposited in the electrolysis bath with various $\mathrm{Sm}$ concentrations $\left(f_{S m}\right)$ were determined by ICP-MS after dissolving the films in an aqueous $\mathrm{HNO}_{3}$ solution. Figure 5 shows the composition of the film precipitated on the Pt electrode under the applied constant potential of $-0.5 \mathrm{~V}$. The Sm ratio in the film monotonically increased with the Sm concentration in the bath. Given the simple relationship between the Sm ratios in the film and the bath, the film composition can be easily controlled by varying the ratio of metal ions in the electrolysis solution. According to Fig. 5, the $f_{S m}$ in the film was lower than that in the bath at $f_{S m}>0.1$. Taking into account the lower solubility of $\mathrm{Sm}(\mathrm{OH})_{3}$ (solubility product: $S_{\mathrm{Sm}(\mathrm{OH}) 3}=$ $\left.4.6^{*} 10^{-23}\right)$ than $\mathrm{Ce}(\mathrm{OH})_{3}\left(\mathrm{~S}_{\mathrm{Ce}(\mathrm{OH}) 3}=7.0^{*} 10^{-21}\right)$ [31], it is reasonable to conclude that the $f_{S m}$ in the film exceeds that in the electrolysis bath. However, the deposited $\mathrm{Ce}(\mathrm{OH})_{3}$ deposited would be oxidized to the tetravalent hydroxide or hydrated oxide by dissolved oxygen molecules derived from the aerated electrolyte solution. Due to lower solubility of the tetravalent cerium compounds $\left(S_{\mathrm{Ce}(\mathrm{OH}) 4}=4 * 10^{-25}\right)[32]$, the $f_{\mathrm{Sm}}$ in the film 
decreased as compared to that in the bath.

\subsection{Crystal structure of as-deposited film}

An XRD analysis was employed to assess the crystallinity of the as-deposited films (Fig. 6). Irrespective of the co-existence of Sm, both XRD patterns displayed the diffraction line assigned to the fluorite structure of $\mathrm{CeO}_{2}$ as well as the Pt substrate. In fact, the appearance of the films was a transparent yellow which corresponded to the original color of $\mathrm{CeO}_{2}$. This indicates the $\mathrm{Ce}(\mathrm{OH})_{3}$ on the Pt substrate had reacted with the dissolved oxygen to form $\mathrm{CeO}_{2}$ during the electrolysis as mentioned above. The oxidation might also proceed during the drying process under ambient conditions. Though the diffraction intensity of $\mathrm{CeO}_{2}$ (111) was relatively low, the film including both $\mathrm{Ce}$ and $\mathrm{Sm}$ has no diffraction lines assigned to $\mathrm{Sm}$ compounds, implying the doping of $\mathrm{Sm}^{3+}$ into the $\mathrm{CeO}_{2}$ lattice. Therefore, Raman spectroscopy was used to confirm the formation of the solid solution (Fig. 7). The pure $\mathrm{CeO}_{2}$ film exhibited a single broad peak at $464 \mathrm{~cm}^{-1}$ due to the symmetric breathing mode of the oxygen atoms surrounding the cations $\left(\mathrm{CeO}_{8}\right)$ [33]. A slight peak shift to a lower wavenumber (454 $\mathrm{cm}^{-1}$ ) was observed in the film prepared in the mixed solution, suggesting that the heavier $\mathrm{Sm}^{3+}$ was present in the $\mathrm{CeO}_{2}$ lattice [34]. Additionally, the broad peak at $500 \sim$ $650 \mathrm{~cm}^{-1}$ that appeared was related to the oxygen defects which originated from the partial substitution of $\mathrm{Sm}^{3+}$ for $\mathrm{Ce}^{4+}$, i.e., $\mathrm{Ce}_{1-\mathrm{x}} \mathrm{Sm}_{\mathrm{x}} \mathrm{O}_{2-\mathrm{y}}$ [35]. These results demonstrated that the electrochemical growth of the $\mathrm{CeO}_{2}$ layer together with $\mathrm{Sm}$ under a cathodic potential induces the incorporation of $\mathrm{Sm}^{3+}$ into the $\mathrm{CeO}_{2}$ lattice in a manner similar to the coprecipitation method for the powder synthesis of doped ceria. It is expected that various kinds of metal ions besides $\mathrm{Sm}^{3+}$ can be dissolved in the lattice. Thus, it can be concluded that the cathodic polarization is useful for the preparation of dense, adherent, crystallized, and doped $\mathrm{CeO}_{2}$ thin films without any heat treatment.

\subsection{Corrosion study}

In past decades, $\mathrm{CeO}_{2}$ coatings have been regarded as a possible alternative to chromate coatings for protecting structural metals. Thus, the barrier effect of the fabricated film on the SUS304 substrate was characterized by measuring the polarization curve in a $0.1 \mathrm{M} \mathrm{NaCl}$ solution (Fig. 8). The cathodic branches of curves did not change before and after the coating, suggesting that the reduction of dissolved oxygen gas occurred at the surface $\mathrm{CeO}_{2}$ layer with a slight electron conductive character. In contrast, the leak current decreased over a wide potential range above the corrosion potential $\left(E_{\text {corr }}\right)$. Similar protection behaviors have been also reported for ceria 
[5] or silica-based conversion coatings [36] on magnesium alloys. The decrease in the anodic current might induce the slight shift of $E_{c o r r}$ to the positive side. Since the film was composed of closely packed nanoparticles as shown in Fig. 4 (b), the aggressive chemical species (ex. $\mathrm{Cl}^{-}$) could not penetrate through the film. Hence, the electrochemical coating in the present study may be useful for improving the anticorrosion properties of steel and/or alloy substrates.

\section{Conclusions}

The present study investigated the electrolysis conditions for the Sm-doped $\mathrm{CeO}_{2}$ thin films having a high density and adhesion. As a result, cathodic polarization was useful for the incorporation of $\mathrm{Sm}^{3+}$ into the fluorite $\mathrm{CeO}_{2}$. It was predicted that $\mathrm{Ce}^{3+}$ and $\mathrm{Sm}^{3+}$ were deposited as hydroxides, in which $\mathrm{Ce}^{\mathrm{III}}$ was transformed into $\mathrm{Ce}^{\mathrm{IV}}$ under an oxidizing atmosphere during the electrolysis. The addition of acetate ions, which coordinate to metal ions, reduced the deposition rate, and then the dense and adherent film with an excellent transparency could be produced on the entire electrode surface. The metal ratio in the film can be easily controlled by varying it in the electrolyte solution. According to the XRD analysis and Raman spectroscopy result, the produced film was crystallized without heat treatment and the $\mathrm{Sm}^{3+}$ dopants were present at the $\mathrm{Ce}^{4+}$ sites of the $\mathrm{CeO}_{2}$. Thus, it can be concluded that the proposed method easily realizes the formation of doped ceria thin films with a high crystallinity, density, and adhesion.

\section{Acknowledgement}

This study was partly supported by Special Coordination Funds for Promoting Science and Technology, MEXT, Japan: "The Nagasaki University Strategy for Fostering Young Scientists".

\section{References}

[1] Z. Shao, S.M. Haile, Nature 431 (2004) 170.

[2] I. Porqueras, C. Person, E. Bertran, Thin Solid Films 447-448 (2004) 119.

[3] T. Masui, M. Yamamoto, T. Sakata, H. Mori, G.-y. Adachi, J. Mater. Chem. 10 (2000) 353.

[4] M. Yamashita, K. Kameyama, S. Yabe, S. Yoshida, Y. Fujishiro, T. Kawai, T. Sato, J. Mater. Sci. 37 (2002) 683.

[5] H. Ardelean, I. Frateur, P. Marcus, Corr. Sci. 50 (2008) 1907.

[6] D.-C. Chen, W.-F. Li, W.-H. Gong, G.-X. Wu, J.-F. Wu, Trans. Nonferrous Met. 
Soc. China 19 (2009) 592.

[7] M.A. Arenas, J.J. de Damborenea, Electrochim. Acta 48 (2003) 3693.

[8] J. A. Switzer, M. G. Shumsky, E. W. Bohannan, Science 284 (1999) 293.

[9] R. Liu, E.A. Kulp, F. Oba, E.W. Bohannan, F. Ernst, J.A. Switzer, Chem. Mater. 17 (2005) 725.

[10] J. A. Switzer, C. J. Hung, B. E. Breyfogle, M. G. Shumsky, R. Van Leeuwen, T. D. Golden, Science 264 (1994) 1573.

[11] Y. Golan, J. L. Hutchison, I. Rubinstein, G. Hodes, Adv. Mater. 8 (1996) 631.

[12] G. S. Hsiano, M. G. Anderson, S. Gorer, D. Harris, R. M. Penner, J. Am. Chem. Soc. 119 (1997) 1439.

[13] Y.-S. Hu, A. Kleiman-Shwarsctein, A.J. Forman, D. Hazen, J.-N. Park, E.W. McFarland, Chem. Mater. 20 (2008) 3803.

[14] Y. Zhou, J.A. Switzer, J. Alloys Compd. 237 (1996) 1.

[15] A.J. Aldykiewicz, Jr., A.J. Davenport, H.S. Isaacs, J. Electrochem. Soc. 143 (1996) 147.

[16] F.-B. Li, R.C. Newman, G.E. Thompson, Electrochim. Acta 42 (1997) 2455.

[17] I. Zhitomirsky, A. Petric, Mater. Lett. 40 (1999) 263.

[18] L. Arurault, P. Monsang, J. Salley, R.S. Bes, Thin Solid Films 466 (2004) 75.

[19] P. Stefanov, G. Atanasova, D. Stoychev, Ts. Marinova, Surf. Coatings Tech. 180-181 (2004) 446.

[20] A.Q. Wang, T.D. Golden, J. Electrochem. Soc. 150 (2003) C616.

[21] T.D. Golden, A.Q. Wang, J. Electrochem. Soc. 150 (2003) C621.

[22] E.A. Kulp, S.J. Limmer, E.W. Bohannan, J.A. Switzer, Solid State Ionics 178 (2007) 749.

[23] K. Kamada, K. Higashikawa, M. Inada, N. Enomoto, J. Hojo, J. Phys. Chem. C 111 (2007) 14508.

[24] Y. Hamlaoui, F. Pedraza, C. Ramazeilles, S. Cohendoz, C. Rébéré, L. Tifouti, J. Creus, Mater. Chem. Phys. 113 (2009) 650.

[25] Y. Hamalaoui, F. Pedraza, L. Tifouti, Corr. Sci. 50 (2008) 2182.

[26] T. Wang, D.C. Sun, Mater. Res. Bull. 43 (2008) 1754.

[27] D. Nickolova, E. Stoyanova, D. Stoychev, I. Avramova, P. Stefanov, Surf. Coatings Tech. 202 (2008) 1876.

[28] A. Mukherjee, D. Harrison, E.J. Podlaha, Electrochem. Solid State Lett. 4 (2001) D5.

[29] Y. Hirata, N. Matsunaga, M. Murao, J. Am. Ceram. Soc. 92 (2009) S11.

[30] E.J. Ruiz, R. Ortega-Borges, L.A. Godínez, T.W. Chapman, Y. Meas-Vong, 
Electrochim. Acta 52 (2006) 914.

[31] T. Moeller, H.E. Kremers, J. Phys. Chem. 48 (1947) 395.

[32] W. Feitknecht, P. Schindler, Pure Appl. Chem. 6 (1963) 126.

[33] S. Kanakaraju, S. Mohan, A.K. Sood, Thin Solid Films 305 (1997) 191.

[34] M.T. Sebastian, N. Santha, P.V. Bijumon, A.-K. Axelsson, N.McN. Alford, J. Eur. Ceram. Soc. 24 (2004) 2583.

[35] A. Mineshige, T. Taji, Y. Muroi, M. Kobune, S. Fujii, N. Nishi, M. Inaba, Z. Ogumi, Solid State Ionics 135 (2000) 481.

[36] J. Hu, Q. Li, X. Zhong, W. Kang, Prog. Org. Coatings 63 (2008) 13. 


\section{Figures}

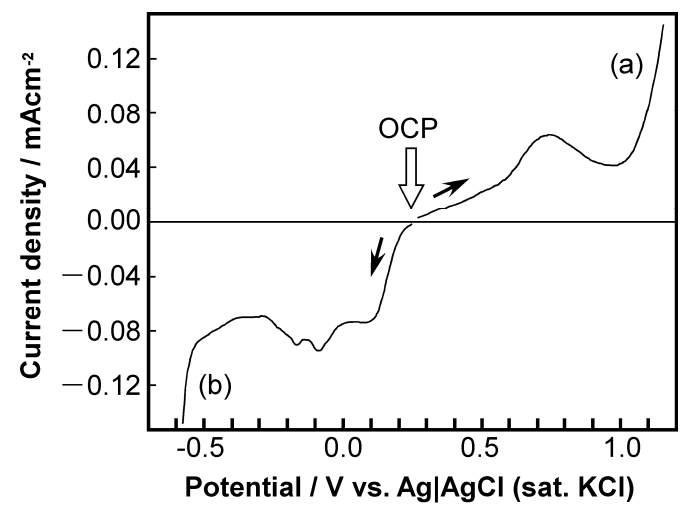

Figure 1: (a) Anodic and (b) cathodic polarization curves $(2 \mathrm{mV} / \mathrm{s})$ of a bare $\mathrm{Pt}$ electrode in the mixed metal solution $\left(f_{S m}=0.5\right)$.

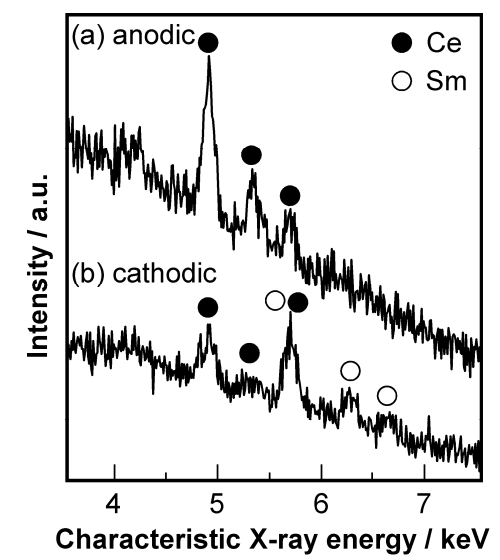

Figure 2: EDS spectra of the films deposited by (a) anodic $(+1.0 \mathrm{~V})$ and (b) cathodic $(-0.5 \mathrm{~V})$ polarizations in the mixed solution $\left(f_{S m}=0.5\right)$, where the detection limit was $\sim 0.2 \mathrm{at} \%$ depending on the element. 


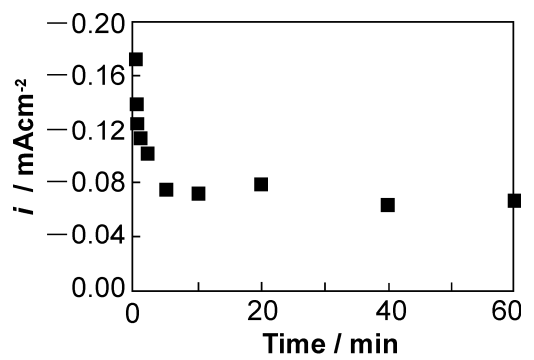

Figure 3: Chronoamperometry of thin film growth on $\mathrm{Pt}$ at $-0.5 \mathrm{~V}$ in the mixed solution $\left(f_{S m}=0.5\right)$.
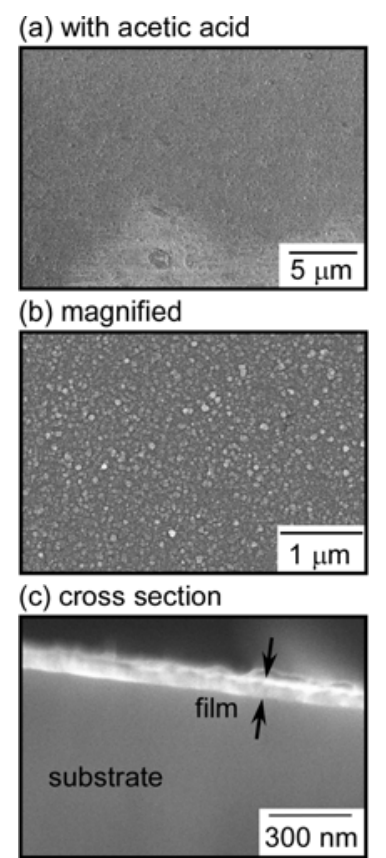

(d) without acetic acid

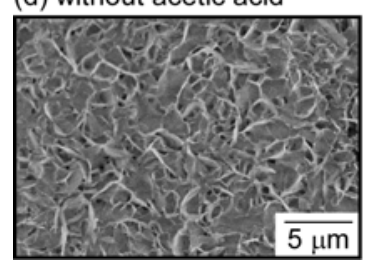

Figure 4: SEM photographs of the surface of the as-deposited film in the mixed solution $\left(f_{S m}=0.5\right)$ with (a) and without acetic acid (d) at $-0.5 \mathrm{~V}$. Magnified and cross-sectional images of (a) are also shown in (b) and (c), respectively. 


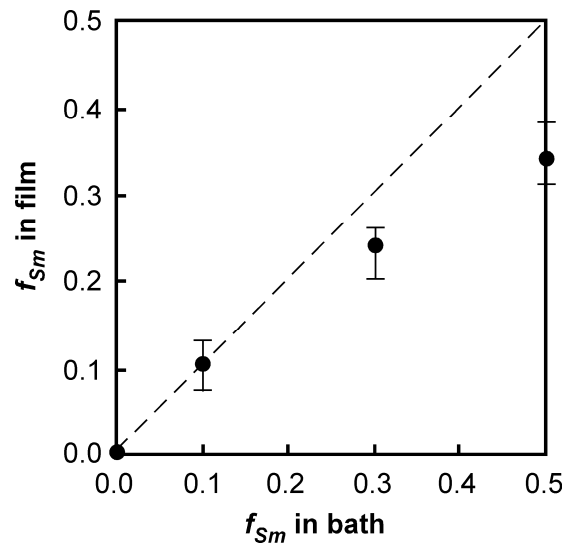

Figure 5: Dependence of bath composition on Sm concentration in the as-deposited film fabricated under the applied constant potential of $-0.5 \mathrm{~V}$.

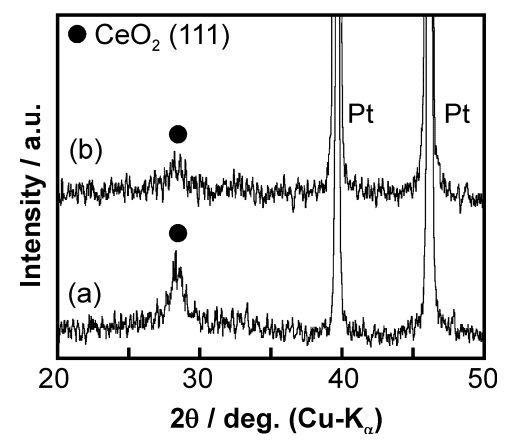

Figure 6: XRD patterns of the films deposited at $-0.5 \mathrm{~V}$ in the mixed solutions $\left(f_{S m}=\right.$ 0 (a) and $0.5(b))$. 


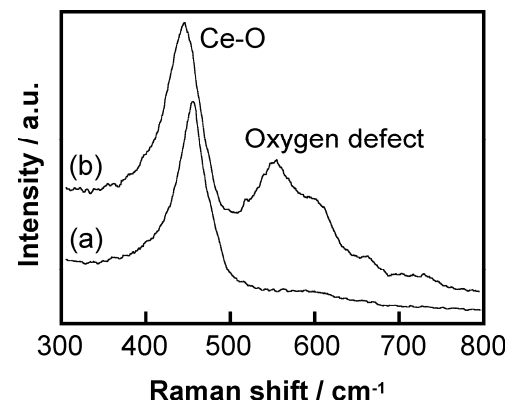

Figure 7: Raman spectra of the as-deposited films formed in the mixed solutions $\left(f_{S m}\right.$ $=0$ (a) and $0.5(\mathrm{~b}))$.

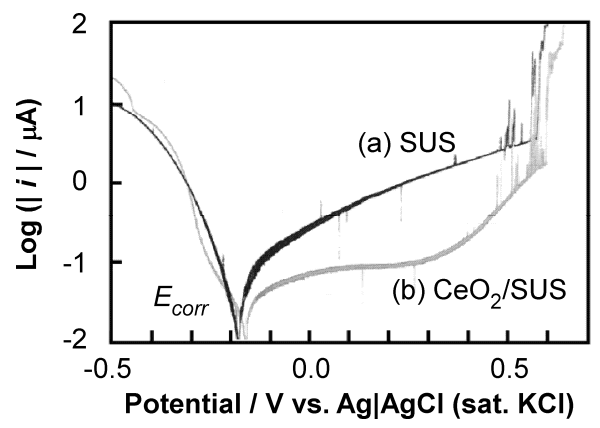

Figure 8: Polarization curves of (a) bare SUS304 and (b) SUS304 covered with electrochemically grown $\mathrm{CeO}_{2}$ layer $(-0.5 \mathrm{~V}$ for $1 \mathrm{~h})$ in $0.1 \mathrm{M} \mathrm{NaCl}$. The apparent electrode area is $0.36 \mathrm{~cm}^{2}$. 